\title{
INFECÇÃO CUTÂNEA POR SCEDOSPORIUM APIOSPERMUM NUM DOENTE IMUNOCOMPROMETIDO TRATADO EFICAZMENTE COM VORICONAZOL
}

\author{
Ana Isabel Gouveia', Leonor Lopes', M. Gomes², Luís Soares de Almeida 3,4, Paulo Filipe 3,4 \\ 'Interna da Formação Específica em Dermatovenereologia/Resident, Dermatology and Venereology Clínica Universitária \\ de Dermatologia, Hospital de Santa Maria, Lisboa \\ 2Serviço de Medicina I B, Hospital de Santa Maria, Lisboa \\ ${ }^{3}$ Professor Doutor do Serviço de Dermatologia e Venereologia/Professor of Dermatology and Venereology, Clínica \\ Universitária de Dermatologia, Hospital de Santa Maria, Lisboa \\ ${ }^{4}$ Instituto de Medicina Molecular, Faculdade de Medicina da Universidade de Lisboa \\ Serviço de Dermatovenereologia, Centro Hospitalar de Lisboa Norte - Hospital de Santa Maria, Lisboa, Portugal
}

\begin{abstract}
RESUMO - Durante as últimas décadas, a incidência de infecções fúngicas oportunistas tem vindo a aumentar, nomeadamente no contexto de imunossupressão. O Scedosporium apiospermum é um fungo filamentoso ubiquitário no solo, vegetação em decomposição, esgotos e em águas poluídas. Pode originar infecções em doentes imunocompetentes após trauma e infecções graves e, potencialmente fatais em doentes imunocomprometidos. Descrevemos um caso de uma infecção por S. apiospermum no dorso do pé esquerdo de um doente sob corticoterapia sistémica prolongada em combinação com metotrexato devido ao diagnóstico de arterite de células gigantes. $O$ tratamento destas infecções pode ser um desafio devido à inerente resistência a muitos dos antifúngicos sistémico disponíveis, incluindo a anfotericina B. No caso descrito, foi realizada terapêutica com voriconazol, com resolução completa das lesões.
\end{abstract}

PALAVRAS-CHAVE - Antifúngicos; Doenças infecciosas da pele; Infecções oportunistas; Scedosporium.

\section{PRIMARY CUTANEOUS INFECTION WITH SCEDOSPORIUM APIOSPERMUM IN AN IMMUNOCOMPROMISED PATIENT SUCCESSFULLY TREATED WITH VORICONAZOLE}

ABSTRACT - During the last decades, the incidence of opportunistic fungal infections has been increasing, namely in the context of immunosuppression. The Scedosporium apiospermum is a ubiquitous filamentous fungus in soil, decaying vegetation, sewers and polluted waters. Can cause infections in immunocompetent patients after trauma and severe and potentially fatal infections in immunocompromised patients. The authors describe a case of an infection by S. apiospermum on the dorsum of the left foot of a patient under prolonged systemic corticosteroid therapy combined with methotrexate due to the diagnosis of giant cell arteritis. Treatment of these infections can be a challenge due to the inherent resistance to many of the available systemic antifungal agents, including amphotericin $B$. In the case described, therapy with voriconazole was performed, with complete resolution of the lesions.

KEY-WORDS - Antifungal agents; Opportunistic infections; Scedosporium skin diseases, Infectious

\footnotetext{
Conflitos de interesse: Os autores declaram não possuir conflitos de interesse.

No conflicts of interest.

Suporte financeiro: $\bigcirc$ presente trabalho não foi suportado por nenhum subsídio ou bolsa.

No sponsorship or scholarship granted.

Direito à privacidade e consentimento escrito / Privacy policy and informed consent: Os autores declaram
} 


\section{Caso Clínico}

que pediram consentimento ao doente para usar as imagens no artigo. The authors declare that the patient gave written informed consent for the use of its photos in this article.

Recebido/Received - Agosto/August 2014; Aceite/Accepted - Setembro/September 2014

Por decisão dos autores, este artigo não foi redigido de acordo com os termos do novo Acordo Ortográfico.

\section{Correspondêncio}

Dr. ․ Ana Isabel Gouveia

Serviço de Dermatovenereologia

Centro Hospitalar de Lisboa Norte

Hospital de Santa Maria

Avenida Prof. Egas Moniz

1649-035 Lisboa, Portugal

Tel.: 00351217805197

\section{INTRODUÇÃO}

Dentro do género Scedosporium existem 2 espécies patogénicas importantes: Scedosporium apiospermum (e a sua forma teleomorfa ou sexuada Pseudallescheria boydii) e Scedosporium prolificans (anteriormente designada de Scedosporium inflatum)'. Estas espécies são ubiquitárias no solo, vegetação em decomposição, esgotos e em águas poluídas. Podem originar infeções localizadas, com extensão para os tecidos circundantes ou disseminar para órgãos à distância'.

Nos últimos anos têm aumentado o número de casos descritos de infecções por Scedosporium apiospermum, provavelmente relacionado com o aumento do uso de terapêuticas imunossupressoras ${ }^{2}$. Este fungo filamentoso pode originar infeções em doentes imunocompetentes após trauma e, infeções graves e potencialmente fatais em doentes imunocomprometidos ${ }^{3}$. As infecções mais frequentes são cutâneas e pulmonares, no entanto, em caso de disseminação hematogénica, podem envolver praticamente qualquer órgão ${ }^{2}$. Este fungo pode originar não só micetomas, mas também pneumonites, osteomielites, artrites, meningites, abscessos cerebrais, endocardites, abscessos da tireóide e granulomas cutâneos e subcutâneos ${ }^{3}$.

\section{CASO CLÍNICO}

Um doente de 71 anos, caucasiano, trabalhador rural, foi referenciado à consulta de Dermatologia por pápulas e nódulos eritematosos e dolorosos no dorso do pé esquerdo acompanhado de ligeiro edema local,
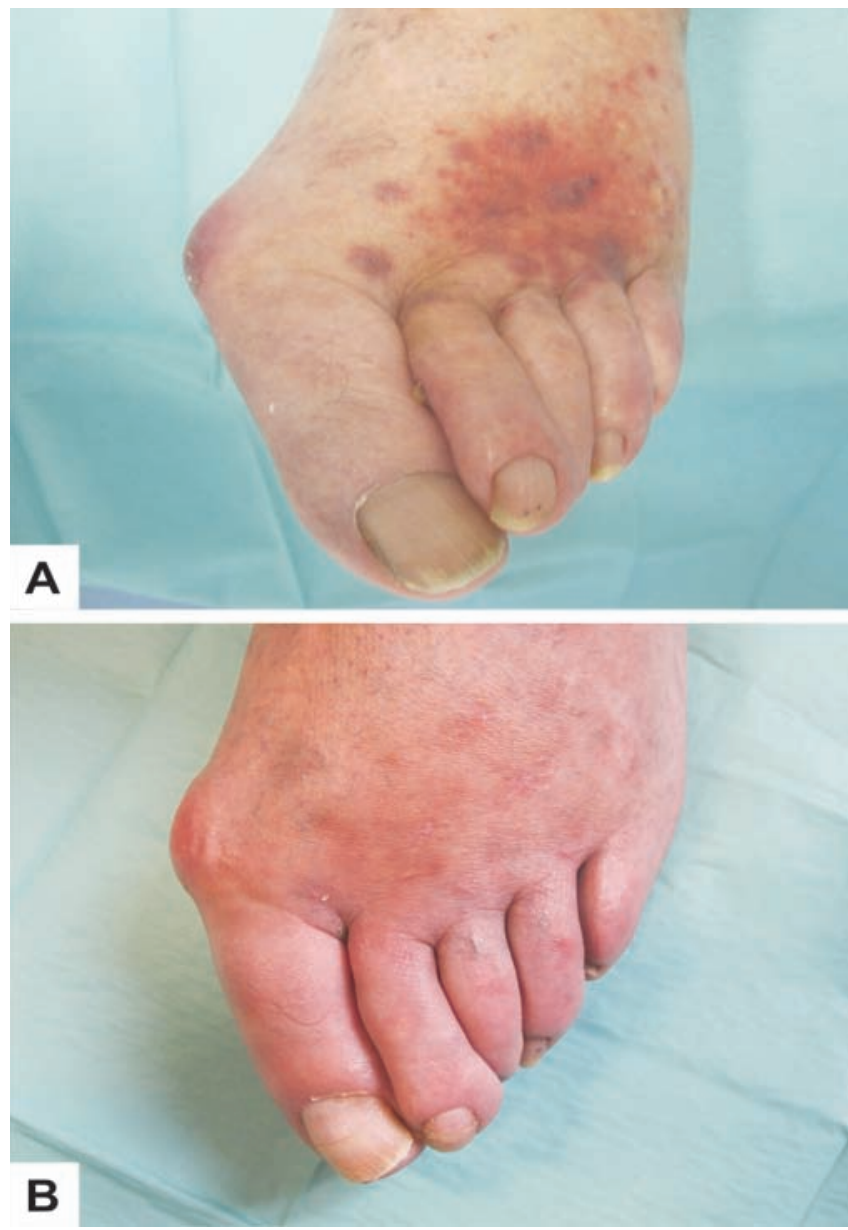

Fig. 1 - (A) Pápulas e nódulos eritematosos no dorso do pé esquerdo; (B) Resolução completa das lesões após tratamento com voriconazol. 


\section{Caso Clínico}
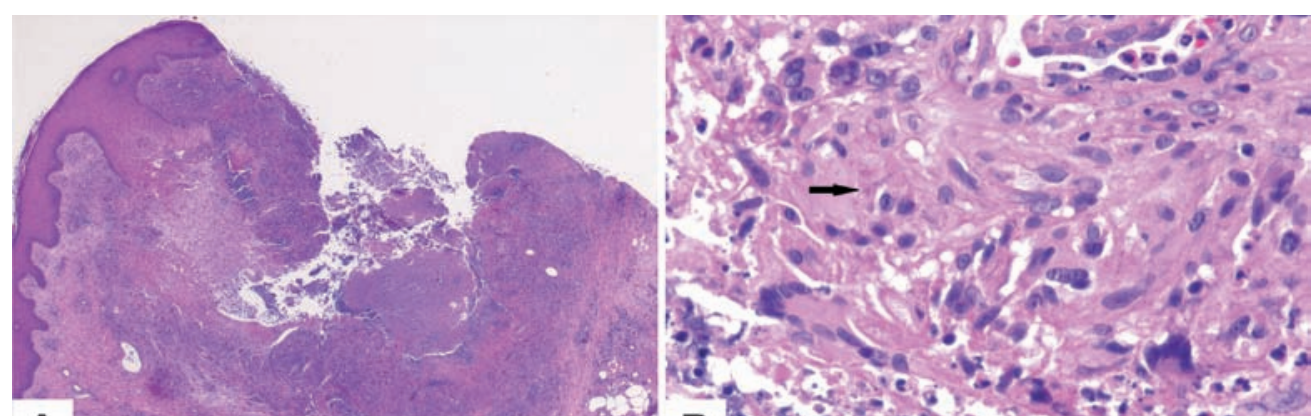

A

B
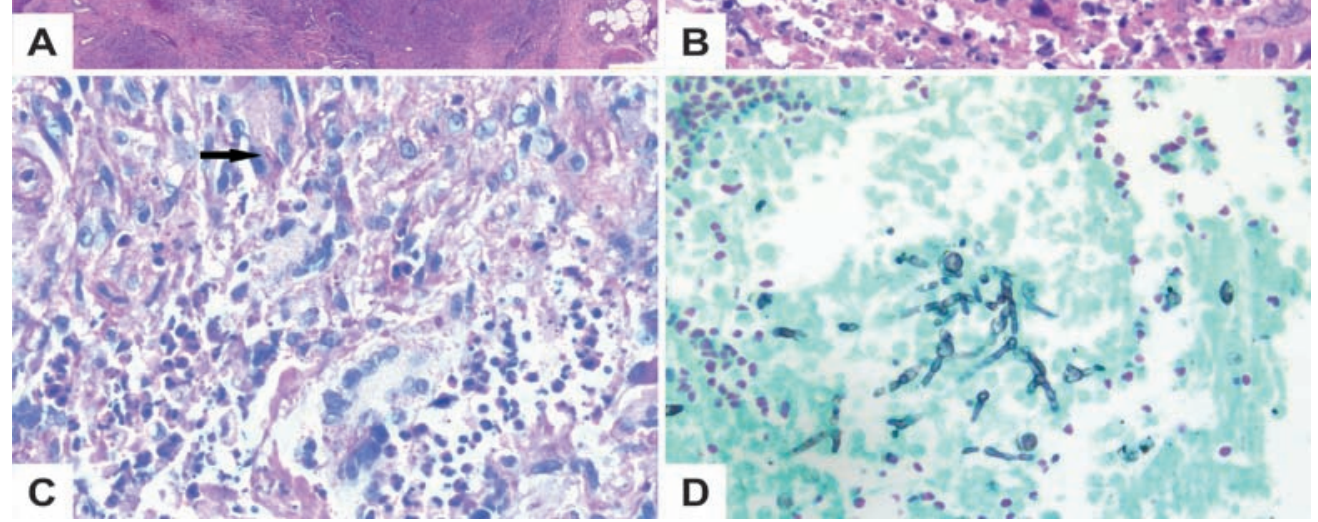

Fig 2 - Exame histopatológico: (A) Hiperplasia pseudoepiteliomatosa da epiderme sobre foco de necrose da derme (H\&E, X25); (B) Granulomas epitelióides intradérmicos e hifas septadas (seta) (H\&E, x400); (C) Hifas septadas dispersas (seta) dentro de células gigantes multinucleadas (PAS, x400); (D) Várias hifas septadas e ramificadas na derme (Grocott, x400).

com cerca de 5 meses de evolução (Fig. 1a). O doente estava sob corticoterapia sistémica prolongada no contexto de arterite de células gigantes (doses iniciais de prednisolona de $80 \mathrm{mg} /$ dia e na data de observação $25 \mathrm{mg} /$ dia) e medicado recentemente com metotrexato (dose de $10 \mathrm{mg} / \mathrm{semana}$ e suspenso há cerca de 1 mês). Doente com múltiplas outras co-morbilidades, nomeadamente diabetes mellitus iatrogénica, insuficiência cardíaca congestiva, doença pulmonar obstrutiva crónica, hiperplasia benigna da próstata e colite ulcerosa.

O doente negava qualquer sintomatologia sistémica acompanhante. No exame dermatológiconão eram evidentes outras lesões cutâneas, e não se palpavam adenopatias. Posteriormente ocorreu fistulização e aumento do edema no dorso do pé esquerdo.

Os exames complementares de diagnóstico, incluindo hemograma com leucograma, imunofenotipagem linfocitária, bioquímica sérica, electroforese de proteínas, doseamento de imunoglobulinas, imunofixação sérica e B2 microglobulina séricas foram normais, as serologias virais (VHB, VHC,HIV) foram negativas. Ausência de reatividade para os anticorpos anti-treponémicos e o sedimento urinário também não revelou alterações.
Foram efetuadas biopsias cutâneas para exame histopatológico, micobacteriológico e micológico. Os exames bacteriológico e micobacteriológico foram negativos. O exame histopatológico com coloração com hematoxilina-eosina revelou hiperplasia pseudoepiteliomatosa da epiderme sobre foco de necrose na derme e granulomas epitelióides intradérmicos (Fig.s $2 a$ e $2 b$ ). A coloração ácido periódico-Schiff (PAS) permitiu demonstrar a presença de hifas septadas (Fig. 2c), confirmado pela coloração de Grocott (Fig. 2d), sendo o fungo filamentoso Sedosporium apiospermum isolado e identificado por exame micológico.

Foram também solicitados exames imagiológicos, nomeadamente ecografia de partes moles e TAC do pé esquerdo, que permitiram excluir colecções abecedadas.

O doente iniciou terapêutica com voriconazol oral, $400 \mathrm{mg}$ bid nas primeiras 24 horas, seguido de $200 \mathrm{mg}$ bid. Durante o seguimento houve elevação das transaminases (ALT com valor duas vezes superior ao limite da normalidade) e a dose de voriconazol foi reduzida para $100 \mathrm{mg}$ bid, com consequente normalização da enzimologia hepática. Após 3 meses de terapêutica houve resolução completa das lesões, observando-se apenas uma ligeira mancha eritematosa residual pós-inflamatória (Fig. 1b), no entanto, optou-se pela 


\section{Caso Clínico}

administração do fármaco durante 6 meses. A resolução do quadro foi confirmado por ecografia de partes moles e por repetição de biopsia cutânea para cultura que se revelaram normal e negativa, respetivamente.

Oito meses após terminação da terapêutica, o doente mantém-se assintomático, sem sinais de recidiva ou reinfeção.

\section{DISCUSSÃO}

Durante as últimas décadas, a incidência de infeções fúngicas oportunistas tem vindo a aumentar, nomeadamente no contexto de imunossupressão ${ }^{3}$.

No caso descrito, os fatores determinantes para uma infeção oportunista incluíram a terapêutica combinada prolongada com prednisolona e metotrexato, e o facto do doente ter desenvolvido diabetes mellitus induzido pelos corticosteróides.

Apesar de não existir história de trauma, é possível que a infeção tenha decorrido de um ferimento local, eventualmente um trauma minor, dado tratar-se de um trabalhador rural.

O tratamento destas infeções pode ser um desafio, não só pela dificuldade em diminuir a imunossupressão em muito destes doentes, mas também devido à resistência inerente destas infeções a muitos dos antifúngicos disponíveis, incluindo a anfotericina $B^{1,4}$. A actividade do voriconazol no tratamento de Scedosporium apiospermum tem sido descrita em vários estudos e casos clínicos, sendo considerado o tratamento de eleição ${ }^{5}$. No entanto, ainda não se sabe qual a duração ideal do tratamento, existindo relatos de recidiva imediata após descontinuação da terapêutica ${ }^{6}$. No nosso doente, apesar da resolução completa das lesões ter sido observada após 3 meses de terapêutica, optou-se pela manutenção de voriconazol até completar 6 meses, dada a possibilidade de recidiva, uma vez que o doente ainda mantinha terapêutica imunossupressora com prednisolona. Como observado no nosso doente, esta opção terapêutica foi eficaz, mantendo-se o doente sem novas lesões 8 meses após terminação da terapêutica.

Os efeitos secundários do voriconazol incluem alterações visuais, hepatite, fotossensibilidade, pseudoporfiria, linfadenopatia e pancitopenia entre outros ${ }^{5}$.
No caso descrito, houve elevação das transaminases com a dose de $200 \mathrm{mg}$ bid (sem outra sintomatologia acompanhante), que reverteu após diminuição da dose e sem compromisso da eficácia terapêutica.

É fundamental estar ciente da importância do diagnóstico precoce e preciso destas infecções, devido à capacidade de disseminação e à resistência à maioria dos antifúngicos sistémicos

\section{Agradecimentos}

Os autores agradecem ao Prof. Heinz Kutzner da Dermatopathologische Gemeinschaftspraxis, Friedrichshafen (Alemanha), pelo apoio no exame histopatológico.

\section{REFERÊNCIAS}

1. Cortez KJ, Roilides E, Quiroz-Telles F, Meletiadis J, Antachopoulos C, Knudsen T, et al. Infections caused by Scedosporium spp. Clin Microbiol Rev. 2008; $21(1): 157-97$.

2. Chaveiro MA, Vieira R, Cardoso J, Afonso A. Cutaneous infection due to Scedosporium apiospermum in an immunosuppressed patient. J Eur Acad Dermatol Venereol. 2003; 17(1):47-9.

3. Uenotsuchi T, Moroi Y, Urabe K, Tsuji G, Koga T, Matsuda T, et al. Cutaneous Scedosporium apiospermum infection in an immunocompromised patient and a review of the literature. Acta Derm Venereol. 2005; 85(2):156-9.

4. Shinohara MM, George E. Scedosporium apiospermum: an emerging opportunistic pathogen that must be distinguished from Aspergillus and other hyalohyphomycetes. J Cutan Pathol. 2009; 36 Suppl 1:39-41.

5. Troke P, Aguirrebengoa K, Arteaga C, Ellis D, Heath $\mathrm{CH}$, Global Scedosporium Study Group, et al. Treatment of scedosporiosis with voriconazole: clinical experience with 107 patients. Antimicrob Agents Chemother. 2008; 52(5):1743-50.

6. Stur-Hofmann K, Stos S, Saxa-Enenkel M, Rappersberger K. Primary cutaneous infection with Scedosporium apiospermum successfully treated with voriconazole. Mycoses. 2011 ; 54(4):e201-4. 